\title{
REPRESENTAÇÕES DE USUÁRIOS, FAMILIARES E PROFISSIONAIS ACERCA DE UM CENTRO DE ATENÇÃO PSICOSSOCIAL
}

\author{
The Conceptions of users, relatives, and professionals about a
} Day-Care Unit

Representaciones de usuarios, familiares y profesionales acerca

de un centro de atención psicosocial

Rosâne Mello ${ }^{1}$

Antonia Regina Ferreira Furegato²

\section{RESUMO}

A partir das mudanças na política de saúde mental, surgiram várias inquietações no que diz respeito ao significado constituído por usuários, familiares e profissionais sobre os Centros de Atenção Psicossociais (CAPS). Este estudo tem como objetivo: Conhecer representações que usuários, familiares e profissionais construíram acerca de um CAPS no Município do Rio de Janeiro. A pesquisa foi realizada com usuários, familiares e profissionais. Seguiu o caminho teórico-metodológico da Teoria Ego-Ecológica, de Marisa Zavalloni. Observou-se que os entrevistados percebem o CAPS através do modelo psicossocial e associam o serviço à redução do número de internações, à inclusão da família e da sociedade no tratamento e à manutenção da liberdade. Os profissionais ressaltam a importância do papel político do CAPS no movimento da Reforma Psiquiátrica. Os profissionais sentem-se pressionados a dar conta da demanda em uma realidade pública caótica que não fornece condições de trabalho, gerando sobrecarga, insegurança e limitações ao trabalho.

Palavras-chave: Reforma dos Serviços de Saúde. Serviços de Saúde Mental. Enfermagem Psiquiátrica.

\begin{abstract}
From the changes in the mental health policies, several questions concerning the conceptions of users, relatives and professionals about a day-care units came up. This paper aims at: knowing the representations that users, relatives and professionals constructed about a day-care unit in the city of Rio de Janeiro. The research was made among users, relatives and professionals and was methodologically based on the Ego-ecologic theory by Marisa Zavalloni. We could notice that people who were interviewed perceived the day-care unit by a psychosocial model in which they associate the unit to the reduction of the number of admissions, the inclusion of the family and society members in the course of treatment, and the preservation of liberty. The professionals reassure that the importance of the political part of the day-care unit in the movement of psychiatric reformation. The professionals feel pressed to deal with the demand of a chaotic public reality that does not offer support to work, resulting in work overload, insecurity and limitations.
\end{abstract}

Keywords: Health Care Reform. Mental Health Services Psychiatric Nursing

\section{Resumen}

A partir de los cambios en la política de salud mental, surgieron varias inquietudes respecto al significado constituido por usuarios, familiares y profesionales sobre los Centros de Atención Psicosocial (CAPS). Este estudio tiene como objetivo: Conocer representaciones que usuarios, familiares y profesionales construyeron acerca de un CAPS en el Municipio de Rio de Janeiro, Brasil. La investigación fue realizada con usuarios, familiares y profesionales. Siguió el camino teóricometodológico de la Teoría Ego-Ecológica de Marisa Zavalloni. Fue observado que los entrevistados perciben el CAPS a través del modelo psicosocial, y asocian el servicio a la reducción del número de internaciones, la inclusión de la familia y de la sociedad en el tratamiento, la manutención de la libertad. Los profesionales destacan la importancia del papel político del CAPS en el movimiento de la Reforma Psiquiátrica. Los profesionales se sienten presionados a dar cuenta de la demanda en una realidad pública caótica que no fornece condiciones de trabajo, generando sobrecarga, inseguridad y limitaciones al trabajo.

Palabras clave: Reforma en Atención de la Salud. Servicios de Salud Mental.Enfermería Psiquiátrica 


\section{INTRODUÇÃO}

Em 2001 foi aprovada a Lei $n^{0} 10.216^{1}$, que se distingue por seus aspectos humanitários, pois perpassa temas que asseguram legalmente a indiscriminação do indivíduo com transtorno mental, bem como seus direitos como cidadão. A partir desta legislação, o Estado se responsabiliza pelo desenvolvimento das políticas de saúde mental, pela assistência e pela promoção das ações de saúde, incluindo a sociedade e a família neste contexto. Dentre os direitos assegurados, podemos citar 0 tratamento humanizado, o direcionamento do cuidado para a permanência ou retorno ao ambiente familiar, comunitário e laboral, a internação hospitalar como último recurso assistencial e proteção contra abuso e exploração.

Para a efetivação da Lei $n \mathbf{0} 10.216^{1}$ foi elaborada a Portaria n- $336^{2}$ que define os Centros de Atenção Psicossocial (CAPS) como "serviços ambulatoriais de atenção diária que funcionam a partir da lógica do território" e visam à integração do usuário à comunidade, assim como sua inserção familiar e social. Com este intuito, os profissionais desenvolvem atividades individuais e em grupo, oficinas terapêuticas, visitas domiciliares, apoio aos familiares e atividades comunitárias. Não basta criar novos espaços de entretenimento para o cliente, faz-se necessário proporcionar-lhe um leque de opções, conforme as necessidades que apresenta ${ }^{3}$.

Não basta modificar os locais de atendimento se não forem modificadas as representações associadas à doença mental, fazendo um movimento que dissocie a loucura da violência, da improdutividade e da incapacidade de articulação social. Por isto, a Reforma Psiquiátrica traz consigo conceitos complexos e inovadores, modificando o foco da atenção do profissional da doença para 0 sujeito, e destaca 0 atendimento em equipe interdisciplinar. A ruptura com o que se entendia como psiquiatria não pode ser feita apenas com a mudança de referenciais, mas precisa ser desenvolvida por meio de ações efetivas na comunidade e pesquisas teórico-práticas que tratem das possibilidades do cuidado no cotidiano.

Apesar dos avanços significativos da assistência psiquiátrica no Brasil, ainda persistem vários desafios para sua consolidação, tais como gastos desproporcionais no pagamento de internações psiquiátricas em hospitais especializados (cerca de $90 \%$ ), ritmo de crescimento insuficiente dos serviços de atenção diária e volume insuficiente de programas sociais para egressos de longas internações ${ }^{4,5}$.

Em 2005, reuniram-se representantes do Ministério da Saúde brasileiro, da Organização Panamericana da Saúde e da Organização Mundial da Saúde com o objetivo de avaliar os resultados da Reforma dos serviços de saúde mental. Neste encontro foi elaborado um relatório ${ }^{6}$ que reafirma os avanços no atendimento em saúde mental nas Américas. Chama atenção para a manutenção do excessivo número de leitos em hospitais psiquiátricos, número escasso de serviços substitutivos inseridos na comunidade e a insuficiência de documentação, monitoramento e avaliação dos serviços.

Com base nestas reflexões, sentiu-se a necessidade de conhecer a percepção daqueles que vivenciam cotidianamente um desses recursos extra-hospitalares, o CAPS, a partir das representações construídas a respeito deste serviço.

\section{OBJ ETIVO}

Conhecer representações que usuários, familiares e profissionais construíram acerca de um Centro de Atenção Psicossocial.

\section{REFERENCIAL TEÓRICO-METODOLÓGICO}

Adotou-se como referencial a Teoria Ego-ecológica, proposta pela psicóloga social Marisa Zavalloni, estudiosa das Representações Sociais. Nesta teoria adota-se o princípio de que o indivíduo é um participante ativo de seu mundo. Buscase compreender a maneira como um ambiente exterior específico (cenário social) se constitui e se organiza em um ambiente interior (o indivíduo). Busca entender as regras e a percepção da realidade que direcionam a conduta de um indivídu0 ${ }^{7}$.

A linguagem é utilizada para compreender 0 sujeito, pois se acredita que esta pode ser usada como instrumento de ação e de reprodução de uma determinada ordem social. As percepções, as lembranças pessoais, as imagens ou as experiências que surgem da memória se revelam através da linguagem. Os significados atribuídos às palavras são utilizados para ampliar o vínculo da linguagem a uma experiência ou a um projeto/objeto específico?.

0 processo de análise utilizado nesta teoria permite conhecer o microcosmo do indivíduo e suas regras mediante as representações que ele constrói sobre cada objeto.

\section{O PERCURSO METODOLÓGICO}

Trata-se de um estudo de abordagem qualitativa, do tipo descritivo, das representações que usuários, familiares e profissionais construíram a respeito de um CAPS.

\section{Cenário}

0 estudo desenvolveu-se no primeiro CAPS gerenciado pela Secretaria Municipal de Saúde do Rio de Janeiro, fundado em maio de 1996. Situa-se fora do espaço hospitalar, possui uma associação de familiares e atua no âmbito de seu território. Localiza-se numa área com 1.300 .000 habitantes e abrange 28 bairros. Vale ressaltar que um CAPS possui capacidade operacional para atendimento de cerca de 200.000 habitantes². Logo, seriam necessários seis CAPS para 0 atendimento desta área.

0 CAPS estudado funciona em uma casa adaptada, de segunda a sexta-feira, das 8 às 17 horas. Em 2005, o CAPS contava com a seguinte equipe multidisciplinar: quatro psicólogas (uma era coordenadora da unidade); quatro médicos psiquiatras; duas pedagogas; duas assistentes sociais; uma nutricionista; uma terapeuta ocupacional; uma enfermeira; duas auxiliares de enfermagem e duas artesãs.

À época do estudo, o CAPS possuía mais de 400 usuários matriculados e chegou a receber cerca de 100 usuários e familiares por dia. 0 número médio de usuários gira em torno de 90 por dia (incluindo os familiares, pode chegar a 120 pessoas por dia). 
0 CAPS oferece várias possibilidades terapêuticas individuais e em grupo. Os atendimentos podem ocorrer com uma periodicidade variável, de acordo com o projeto terapêutico estabelecido entre usuário e profissional e as possibilidades do serviço. As atividades oferecidas pelo CAPS são atendimentos individuais, em grupo, ambulatorial, visita domiciliar, oficinas e atividades desenvolvidas no entorno do serviço.

\section{Perfil dos participantes do estudo}

Participaram 11 usuários, 11 familiares e 12 profissionais do CAPS, o que possibilitou aproximações e afastamentos acerca das representações construídas acerca do serviço. Permitiu acesso à percepção dos grupos isoladamente, assim como do conjunto, oferecendo maior possibilidade de compreensão dos temas abordados.

Os critérios de seleção dos usuários foram os seguintes: idade superior a 21 anos, ser portador de transtornos mentais graves, cuja primeira crise tenha ocorrido há pelo menos três anos, e ser atendido regularmente no CAPS há no mínimo três anos. Foi imprescindível que o usuário estivesse fora de crise. No que diz respeito aos familiares, participaram aqueles que compareciam pelo menos a uma das atividades semanais do CAPS. Dos profissionais que atuam diretamente no cuidado aos usuários, somente dois optaram por não participar do estudo.

Inicialmente pretendia-se fazer uma triangulação entre os grupos de participantes do estudo, porém, não foi possível. Quando se iniciou o trabalho de campo, observou-se que os familiares dos usuários que tinham condições de participar do estudo não compareciam ao CAPS. Por sua vez, os familiares que compareciam eram parentes de usuários em crise.

Os usuários foram de ambos os sexos, a maioria tinha entre 30 e 49 anos e ensino fundamental incompleto. A maioria morava com a família, porém seus familiares compareciam ao CAPS esporadicamente. Observou-se que cinco usuários trabalhavam informalmente e não possuíam renda fixa, seis dependiam de aposentadoria, seguro-saúde ou da família. Oito entrevistados freqüentavam o CAPS por mais de quatro anos, a maioria tinha convivido com a doença mental há 10 anos ou mais e tinha diagnóstico médico de esquizofrenia. Seis entrevistados foram reinternados até quatro vezes em hospitais especializados após o início do atendimento no CAPS.

A maioria dos familiares eram mães de usuários, com mais de 50 anos de idade e com ensino fundamental incompleto. 0 núcleo familiar mais freqüente era composto por até três indivíduos, com renda mensal igual ou inferior a dois salários mínimos e com moradia própria. A maioria destes familiares participava do Grupo de Família.

Participaram deste estudo profissionais graduados (três psicólogas, três médicos, duas pedagogas, duas assistentes sociais, uma enfermeira e uma nutricionista), sendo a maior parte do sexo feminino e com menos de 50 anos de idade. A maioria trabalha no CAPS e atua na área de saúde mental há mais de cinco anos, sete são funcionários públicos municipais e cinco são contratados pela Organização Não Governamental
Instituto Franco Basaglia; quatro trabalham apenas no CAPS e oito possuem dois ou mais empregos. Dentre os entrevistados, seis fizeram especialização, quatro, residência, e dois, mestrado. Todos fazem atendimento individual, nove fazem atendimento em grupo, e sete profissionais coordenam oficinas terapêuticas. Metade deles realiza algum tipo de atividade externa ao CAPS.

\section{Os instrumentos}

Para a coleta de dados foram utilizados dois instrumentos. 0 primeiro foi nomeado Instrumento de Contextualização do Sujeito (ICS), com o qual se buscou conhecer os participantes do estudo e que foi dividido em duas partes: a) Levantar informações pessoais e sociais e b) Descrever a participação do sujeito nas atividades do CAPS

0 segundo instrumento foi o Inventário Multifásico de Identidade Social (IMIS), construído a partir da Teoria Egoecológica, e teve como referência o Inventário de Zavalloni. Seu objetivo foi o de identificar as representações do indivíduo acerca de si mesmo, dos seus pares e dos grupos com os quais se relacionava dentro do contexto do CAPS, assim como as representações e expectativas a respeito do CAPS.

0 IMIS acessa as representações do sujeito através da complementação de frases acerca de um determinado tema (Por exemplo, "O CAPS é..."). Foi solicitado que o participante indicasse três atributos para cada frase apresentada. Em um segundo momento, pediu-se que informasse se os atributos indicados estavam relacionados a ele. Na terceira etapa, 0 entrevistado classificou os atributos em positivos ou negativos.

\section{Cuidados éticos e a coleta de dados}

0 projeto foi aprovado pelo Comitê de Ética do Hospital Municipal Souza Aguiar, assim como pela equipe do CAPS, em reunião de supervisão.

As entrevistas individuais foram realizadas nas dependências do CAPS. Ao iniciar a entrevista, foi esclarecido o objetivo do estudo e reforçada a garantia do anonimato, e 0 "Termo de Consentimento Livre e Esclarecido" foi lido e assinado por todos os sujeitos.

\section{ANÁLISE DOS DADOS}

Os temas emergentes da fala dos entrevistados foram analisados e classificados em eixos temáticos, através dos quais foram observados os campos simbólicos onde se depositavam as realizações, os projetos e os desejos de cada indivíduo.

A análise permitiu identificar os conteúdos individuais e os conteúdos coletivos de cada tema emergente do discurso de cada participante. A análise ocorreu através da complementação, contradição e sobreposição das respostas dos três grupos de entrevistados. Optou-se por discutir as quatro categorias mais freqüentes.

Com estes dados, foi possivel conhecer as representações, elucidar 0 quanto estão arraigadas e 0 nível de percepção sobre as mesmas, o que permitiu passar de um conceito abstrato para referenciais empíricos, assim como reduzir o número de inferências do pesquisador no momento da análise. 


\section{APRESENTAÇÃO E DISCUSSÃO DOS RESULTADOS}

\section{A - Representações de usuários, familiares e profissionais acerca do CAPS}

0 tema Reabilitação Psicossocial foi o mais encontrado $(40,2 \%)$ na fala dos entrevistados e diz respeito às características relativas ao modelo psicossocial de atendimento. 0 tema foi observado na fala de todos os grupos de participantes do estudo. Este fato indica que usuários, familiares e profissionais entrevistados retratam o CAPS através de características correlatas à atual política de saúde mental. As conotações observadas percorrem tanto questões objetivas da política quanto questões relativas à tecnologia leve do cuidado.

A reabilitação psicossocial é definida como uma série de intervenções sociais, educacionais, ocupacionais, comportamentais e cognitivas que tem como objetivo incrementar a capacidade de desempenho dos papéis sociais das pessoas com algum tipo de doença mental grave e persistente, de forma tal que sua recuperação fique evidenciada? ${ }^{9}$.

Destacam-se nas falas dos entrevistados premissas do processo de reabilitação psicossocial correlacionadas ao CAPS, tais como a redução do número de internações e 0 incremento da auto-estima

Depois que conhecio CAPS, nunca mais me internei; - CAPS é um centro de reabilitação para quem quer se amar, cuidar. (Usuário)

Neste sentido, os novos locais de atendimento precisam ser espaços de produção de sentido, de circulação de afeto, da criatividade, da alegria e da solidariedade ${ }^{10}$. Tais afirmações vão ao encontro da definição de CAPS observada na fala dos usuários, pois vão além da descrição técnica, indicando a valorização do ser humano.

$\mathrm{Na}$ fala dos familiares entrevistados, destacam-se a inclusão da família e da sociedade no cuidado, a preservação da liberdade do usuário e a regionalização do atendimento

O CAPS influencia a sociedade de forma positiva, porque influencia os familiares também; tem os portões abertos, sem grades; fica mais perto das pessoas que se tratam (Familiar)

Não há como negar que se torna mais fácil enfrentar 0 estigma, pois nessa nova proposta a comunidade é envolvida como constituinte da rede social do serviço ${ }^{10}$. A família, dessa forma, se torna sujeito solidário de uma nova cultura.

$\mathrm{Na}$ fala dos profissionais entrevistados, destacam-se questões relativas ao papel do CAPS na política atual de saúde mental, 0 direito à cidadania do usuário e a ressignificação do conceito de loucura

O CAPS é uma unidade de assistência essencial para a Reforma Psiquiátrica; é o local para alcançar a cidadania; é o exercício de uma mentalidade renovada na relação com a loucura. (Profissional)
As declarações dos profissionais mostram que são importantes as características arquitetônicas e 0 trabalho interdisciplinar, mas principalmente a prática do diálogo e 0 respeito à singularidade e aos direitos dos usuários. $\mathrm{Na}$ participação ativa do usuário em seu próprio tratamento está o futuro de um sistema de atendimento bem-sucedido em sua finalidade de cuidar e garantir que as forças autocurativas, de estabilidade ou reintegração sejam mais bem aproveitadas ${ }^{10}$.

0 segundo tema mais incidente na fala dos entrevistados foi Conteúdo Avaliativo (15,7\%). Analisa as percepções dos entrevistados e o juízo a respeito do CAPS. Este tema pode ser avaliado através de dois caminhos: a qualidade do atendimento no CAPS, presente nos três grupos, e a dependência do usuário ao serviço, presente na fala de familiares e profissionais.

0 tratamento oferecido no CAPS é analisado de forma positiva pelos entrevistados:

O CAPS é um dos melhores tratamentos por que já passei (Usuário)

É, para o tratamento desta doença, o melhor que já vi (Familiar)

Dentre os usuários entrevistados, 90,9\% têm um tempo de diagnóstico igual ou superior a dez anos e 63,7\% já tiveram três ou mais internações em hospitais psiquiátricos. Quando os usuários comparam os serviços por onde já passaram e 0 CAPS, a qualidade deste último se destaca. Observamos na fala dos familiares o impacto causado pela situação de adoecimento e internação psiquiátrica, indo ao encontro do que já foi descrito anteriormente ${ }^{11,12}$.

A percepção de uma prática mais adequada também é observada na fala dos profissionais

O CAPS é um local onde é possivel exercer uma boa prática clínica. (Profissional)

Os profissionais e familiares ressaltam a dependência do usuário em relação ao serviço, sendo o CAPS o único espaço de troca social:

O CAPS é tudo para o meu filho (Familiar)

É tudo na vida para a maioria dos usuários (Profissional)

Faz-se necessário observar o perigo deste processo, no qual o sujeito, através de sua enfermidade, estabelece relação de dependência com os profissionais, utilizando lugares e pessoas de forma ritualizada. Sua vida pode ficar condicionada pelas diferentes 'instituições' do setor, cada qual detentora de um potencial de cronicidade ${ }^{13}$.

Os profissionais chamam a atenção para uma possível cronificação dos usuários, principalmente quando se reflete que $33,3 \%$ dos usuários do referido CAPS estão em atendimento há mais de dois anos e $72,7 \%$ estão no CAPS há mais de quatro anos. 
Durante a coleta de dados no serviço, principalmente durante as reuniões de supervisão, observou-se que, apesar de esta ser uma preocupação constante dos profissionais, é grande a dificuldade em encontrar a solução deste problema e trabalhar para incrementar a autonomia do cliente.

0 terceiro tema mais evidente foi Sobrecarga $(11,8 \%)$, sendo 0 segundo mais saliente na fala dos familiares. Indica um encargo maior do que o esperado ou planejado. Para os familiares, o CAPS está relacionado ao alívio da sobrecarga gerada pelo convívio prolongado e continuado com as questões relativas ao transtorno mental:

0 CAPS é um lugar de convivio, onde os familiares podem colocar suas dificuldades através dos grupos; é um lugar seguro para o meu filho; é um lugar onde posso falar o que estou sentindo; é o apoio que não tive em lugar nenhum. (Familiares)

As atividades de apoio oferecidas aos familiares são: grupo de família, atendimentos individuais e nucleares, 0 que vai ao encontro de estudos que ratificam a importância da inclusão da família no projeto terapêutico do cliente ${ }^{12}$.

Apenas $14,8 \%$ dos clientes entrevistados têm, em seu projeto terapêutico, algum tipo de atendimento aos seus familiares. Como as entrevistas foram realizadas com os familiares no próprio cenário do estudo, ficaram fora da amostra aqueles que não comparecem ao CAPS.

$\mathrm{Na}$ fala dos profissionais, observa-se um outro lado do tema Sobrecarga, relacionado, principalmente, ao cansaço e ao desgaste causado pelo trabalho no CAPS. Esta situação de sobrecarga confirma-se através da comparação entre os dados que caracterizam o serviço e o que é preconizado². 0 CAPS está inserido em uma área com cerca de 1.300 .000 habitantes, enquanto o preconizado é entre 70 e 200 mil habitantes ${ }^{14}$.

Além do excesso de demanda pelo serviço, a Secretaria Municipal de Saúde do Rio de Janeiro encontrava-se em crise no período de realização deste estudo. No período de coleta dos dados foi possível observar a falta de alimentos e medicamentos para os usuários, assim como de material para a realização das oficinas, deixando não somente os profissionais sob tensão, como também usuários e familiares.

0 quarto tema mais freqüente foi Aspectos relativos à família. Este tema esteve presente na fala dos três grupos entrevistados, porém destacou-se entre os usuários:

O CAPS é uma casa, minha segunda casa; é como uma familia; é uma familia grande. (Usuário)

Dentre as atribuições da família, menciona-se a proteção de seus membros, através de apoio afetivo, psicológico e material, bem como a transferência de valores, hábitos e comportamentos culturais ${ }^{15}$. Vale ressaltar que algumas características do cuidado referenciadas pelo modelo psicossocial assemelham-se aos cuidados esperados em um grupo familiar. 0 longo tempo de permanência do usuário no serviço e a vivência de um processo terapêutico potencializam as habilidades dos usuários e a criação de vínculo entre usuários e profissionais do CAPS.

\section{B - Representações de usuários, familiares e profissionais acerca do que poderia melhorar no CAPS}

Dentre os temas que emergiram das falas dos sujeitos, no que concerne ao que poderia melhorar no CAPS, 0 mais freqüente foi $(25,5 \%)$ Estrutura do cuidado, que fala sobre 0 modo como 0 CAPS está organizado para atender às demandas emergentes. Os usuários afirmam que gostariam que houvesse mais atividades no CAPS

0 CAPS poderia ter mais coisas para aprender; poderia ser mais organizado, ter mais festas e mais pessoas; poderia ter mais terapias profissionalizantes. (Usuário)

0 serviço oferece mais de 30 atividades diferentes. Possivelmente, os usuários estão solicitando uma diversificação das atividades oferecidas pelo serviço, principalmente daquelas que têm como objetivo a produção de renda. Neste contexto, as atividades ocupacionais são de grande importância, pois influenciam diretamente na performance social da pessoa com transtorno menta| ${ }^{16}$.

A percepção dos familiares é semelhante a dos usuários, sugerindo que o número de atividades seja incrementado, tanto aquelas associadas à geração de renda como as relativas às atividades sociais, que têm como objetivo:

o CAPS poderia ter mais passeios, como antigamente; poderia ter mais atividades práticas profissionalizantes; poderia ter mais oficinas de trabalho para familiares e pacientes; poderia dar emprego para os familiares. (Familiar)

Observou-se a questão da desqualificação social, gerada pela pobreza, acrescida à sobrecarga do transtorno mental, e que a dificuldade em inserir-se no mercado de trabalho formal leva a uma situação econômica frágil. Sua expectativa é no mínimo intrigante e questionável quando solicita ao CAPS formação profissional para o familiar.

A criação de atividades geradoras de renda destaca-se na fala de usuários e de familiares. 0 CAPS surge para usuários e familiares a partir de uma expectativa que vai além do cuidado do transtorno mental, mas como o lugar que instrumentalizará a redução da sobrecarga familiar em muitos sentidos, inclusive econômico.

Familiares esperam do CAPS funções tão amplas que tangem o modelo asilar, no que diz respeito a guarda do usuário

O CAPS poderia ficar direto com os pacientes, de segunda a sexta-feira. (Familiar)

Os profissionais precisam estar atentos, pois, diante de uma clientela carente, as características do modo asilar de atendimento (no qual a instituição tende a funcionar como espaço depositário, de tutoria e de agenciadora de suprimentos) podem ser as ambicionadas pelos familiares e reproduzidas dentro do espaço do CAPS $^{17}$. 
Os profissionais apresentam expectativas diversas ao que poderia melhorar no CAPS, mais próximas às questôes organizacionais:

O CAPS poderia ser mais bem organizado, com recursos materiais e humanos; poderia ser melhor estruturado; poderia ser mais articulado com as outras instituições sociais. (Profissional)

A percepção dos profissionais está diretamente ligada às dificuldades que enfrentam no cotidiano de seu trabalho, principalmente no que diz respeito à falta de recursos materiais para 0 desenvolvimento de suas funções e 0 atendimento de melhor qualidade. Tal percepção também vai ao encontro do excesso de usuários que atendem diariamente, indicando a necessidade de mais profissionais para o serviço, ou até mesmo a criação de mais CAPS para dar conta da necessidade da população.

0 estabelecimento de parcerias é importante para 0 funcionamento dos CAPS, pois, no trabalho em rede de apoio, a intersetorialidade é essencial. Inserir na sociedade os diferentes significa intervir na sociedade para que esta mude seus padrões e regras do "bem-viver", de convívio, da solidariedade, devolvendo a vida a essas pessoas ${ }^{18}$.

As demandas de usuários e familiares são muitas e suscitam interlocução com vários setores como saúde, educação, lazer e outras. A sociedade precisa ser incluída nas propostas de atendimento em saúde mental, pois, para se substituírem os hospícios, é necessário ter fé e confiança no doente, em sua criatividade e em seu potencial ${ }^{11}$.

0 tema Estrutura do cuidado, na fala dos profissionais, indica que 0 atendimento aos usuários ainda está baseado em uma visão asilar. 0 sujeito continua sendo percebido através dos sintomas da doença, e não através de sua subjetividade

O CAPS poderia ser menos infantilizador; poderia ser menos moralista. (Profissional)

0 segundo tema mais freqüente sobre as recomendações para melhorar 0 atendimento foi Recursos materiais $(17,6 \%)$. Este eixo temático esteve presente na fala de usuários e de familiares:

O CAPS poderia ter mais remédios (Usuário); poderia ter refeições direito para os pacientes (Familiar)

Tanto usuários como familiares reivindicam alimentação e medicamentos psicoativos. Os usuários reivindicam, prioritariamente, alimentação de qualidade, enquanto os familiares reivindicam medicamentos, ou seja o peso dessas necessidades diferencia-se entre os sujeitos. Como estes usuários se alimentam diariamente no CAPS, esta é a necessidade mais afetada no dia-a-dia. Os usuários podem estar percebendo o tratamento como algo além da medicação e valorizando mais efetivamente 0 suporte social e psíquico recebido no CAPS. Desta forma, o modelo psicossocial está na significação que os usuários entrevistados dão ao tratamento. 0 mesmo não acontece entre os familiares, que continuam percebendo 0 tratamento através do modelo asilar, centrado nas questões biomédicas da assistência:

\section{O CAPS tinha que melhorar a comida (Usuário)}

\section{Poderia ter mais medicação (Familiar)}

0 terceiro tema mais freqüentemente sobre as alterações que poderiam ser feitas na estrutura física do CAPS para melhor atender às demandas dos participantes foi Estrutura física, (14,7\%). A inadequação do tamanho do CAPS em relação a sua demanda foi mencionada:

0 CAPS poderia ter mais salas de atendimentos, banheiros (Usuário)

Poderia ter uma área melhor de lazer (Familiar)

As salas são pequenas e inadequadas para as atividades em grupo, e a climatização não dá conta do movimento humano. $\mathrm{Na}$ instituição existem apenas três banheiros com chuveiro, sendo dois para os usuários e seus familiares (um para o sexo masculino e outro para o feminino) e um para os profissionais e demais funcionários do serviço, o que é insuficiente para a demanda diária.

A Desatenção governamental foi o quarto tema mais freqüente $(11,8 \%)$. Na percepção dos entrevistados, o suporte oferecido pelo governo não é suficiente para o funcionamento adequado do CAPS:

O CAPS poderia ter mais verbas direcionadas para o CAPS (Usuário)

\section{Poderia ter mais apoio do governo (Familiar)}

Na administração do setor de saúde do Rio Janeiro, observase uma batalha entre os niveis de governo. Quem arca com 0 maior prejuízo é a população, já massacrada por outros problemas sociais. Esta batalha tem se caracterizado mais por seus aspectos políticos do que pela preocupação com a resolução de problemas do setor saúde. 0 descaso dos políticos, as medidas decisórias e executivas em relação ao setor saúde têm gerado sobrecarga nas instituições e nos profissionais que nelas atuam, o que está deixando a população desprovida do seu direito à saúde, "garantido" na Constituição brasileira.

0 tema Modelo Psicossocial (10,8\%) foi o quinto mais freqüente no computo geral, porém, foi o mais freqüente na fala dos profissionais e trata das características do atendimento 
no CAPS. Os profissionais trouxeram duas questões que gostariam que fossem for tificadas ou modificadas: a relação do CAPS com o território e a inserção dos usuários no contexto social. Os profissionais afirmam:

0 CAPS poderia consolidar-se como articulador efetivo da rede de saúde; poderia ser umagenciador efetivo da inserção sócio-cultural; poderia ser uma passagem temporária. (Profissional)

A fala dos profissionais indica sentimentos de frustração, quando verbalizam as dificuldades encontradas no modo psicossocial de cuidar, alegando que ainda não foram encontradas possibilidades de solução. Dentre os obstáculos citados, está a efetivação da inserção social das pessoas com transtornos mentais graves e de longa duração no contexto social e a saída do usuário do CAPS para a vida. Os profissionais têm dificuldades para desenvolver o papel de organizador da rede de saúde mental do território onde está inserido.

A falta de preparo dos profissionais para 0 atendimento de pessoas com transtornos mentais graves, de longa duração e em uma situação sócio-econômica desfavorável pode ser um problema enfrentado no contexto da reabilitação psicossocia ${ }^{13}$. 0 despreparo dos profissionais para esta clientela tão específica pode gerar nos profissionais sentimentos de frustração e culpa.

Fica claro que o cuidado à pessoa com transtorno mental grave e de longa evolução necessita ser visto por prismas que vão além do modelo asilar, centrado nos profissionais médico e enfermeiro, bem como na administração e controle dos medicamentos psicoativos. Atualmente, a necessidade de cuidado vai além, expandindo-se ao campo residencial, esportivo, de trabalho, recreacional e cultural. Isto indica a necessidade de mudanças no conceito de saúde, indicando a necessidade de um atendimento ampliado e, possivelmente, baseado na intersetorialidade.

Alguns anos atrás, possivelmente encontraríamos resultados diferentes dos observados neste estudo, em que a importância das questões relativas à inserção social foi tão estimada. Apesar de todos os avanços no campo da saúde mental no Brasil, verifica-se que muito trabalho ainda está por vir, principalmente no que diz respeito aos profissionais e aos familiares dos usuários do CAPS. No que tange aos portadores de transtorno mental, acredita-se que, quando novas possibilidades de cuidado thes forem apresentadas e havendo possibilidade de escuta do seu desejo, outros recursos terapêuticos poderão ser implementados e incorporados aos serviços de saúde mental.

\section{CONSIDERAÇÕES FINAIS}

Este trabalho teve como objetivo refletir sobre os resultados da atual política de saúde mental, a partir das representações construídas acerca de um CAPS. Pretende-se contribuir para que os gestores da saúde mental conheçam mais de perto seus principais sujeitos, ou seja, portadores de transtorno mental, seus familiares e profissionais.

0 presente trabalho pode contribuir para que os profissionais percebam de forma mais clara a dinâmica do seu cotidiano. Em razão da formação profissional, da sobrecarga de trabalho e da falta de condições mínimas para exercer suas atividades, 0 profissional cria mecanismos que muitas vezes obscurecem seu principal objetivo, ajudar o sujeito com transtorno mental a ter melhores condições de vida (o cuidado).

Possibilitou-se ao sujeito com transtorno mental falar em seu próprio nome e conhecer sua visão sobre o CAPS. Foi possivel tirá-lo do lugar de louco/passivo, ressignificando sua condição para cidadão/ativo com sonhos e esperanças.

A análise dos significados atribuídos ao CAPS por usuários, familiares e profissionais do serviço e as expectativas nutridas por estes sujeitos acerca desta instituição permitiram chegar a algumas conclusões:

- Os entrevistados percebem o CAPS através do modelo psicossocial, sob diferentes perspectivas: os usuários ressaltam a redução do número de internações e 0 incremento de sua auto-estima; os familiares destacam a importância da inclusão da família e da sociedade no tratamento e a manutenção da liberdade dos usuários; os profissionais ressaltam a importância do papel político do CAPS no movimento da Reforma Psiquiátrica, o resgate da cidadania do usuário e a ressignificação do conceito de loucura.

- Os usuários e familiares percebem a assistência no CAPS através do cuidado, enquanto os profissionais percebem a assistência através da política de saúde mental.

- Alguns familiares percebem o CAPS através de uma perspectiva assistencialista, como no modelo asilar. Eles esperam que o CAPS resolva problemas referentes à sobrecarga gerada pelo convívio com o transtorno mental, o desemprego e a distribuição de renda.

- As expectativas dos usuários e dos familiares, no que concerne ao CAPS, vão além do que este serviço se destina.

- Os profissionais sentem-se pressionados a dar conta da demanda em uma realidade pública caótica que não fornece condições de trabalho, gerando sobrecarga, insegurança e limitações no trabalho.

0 presente estudo mostrou que, apesar das dificuldades encontradas, o modo psicossocial de atendimento tem beneficiado a pessoa com transtorno mental, porém observase cer ta paralisação no movimento da Reforma Psiquiátrica no cenário do CAPS. Foi criado um modelo assistencial que beneficia a pessoa com transtorno mental, contudo corre-se o risco de uma cronificação destes sujeitos dentro do CAPS. 0 CAPS não deve transformar-se em casa, família ou local de refúgio, mas no local onde usuários e familiares recebam supor te terapêutico adequado e onde seja possibilitada a continuação de sua vida e suas contingências. 


\section{Referências}

1- Lei ํㅜ 10.216, de 6 de abril de 2001. Dispõe sobre a proteção e os direitos das pessoas portadoras de transtornos mentais e redireciona o modelo assistencial em saúde mental. Diário Oficial da República Federativa do Brasil, Brasília (DF), 9 abr 2001. Seção 1:2. 2-Portaria n 336/GM, de 19 de fevereiro de 2002. Estabelece que os Centros de Atenção Psicosso cial poderão constituir-se nas seguintes modalidades de serviço: CAPS I, CAPS II E CAPS III. Diário Oficial da República Federativa do Brasil, Brasília (DF), 20 fev 2002. Seção 1:22.

3-Saraceno B. Libertando identidades- da reabilitação psicossocial à cidadania possível. Belo Horizonte (MG): TeCorá; 1999.

4-Mello R, Furegato ARF. Internações psiquiátricas no Rio de janeiro de 1996 a 2005. Rev Enferm UERJ 2007; 15(2): 176-82.

5-Oliveira AGB. Trabalho e cuidado no contexto da atenção psicossocial: algumas reflexões. Esc Anna Nery Rev Enferm 2007;10(4): 694-702

6-Ministério da Saúde (BR). Princípios orientadores para 0 desenvolvimento da atenção em saúde mental nas Américas. In: Rolim M. Direitos humanos e segurança pública. [citado 27 abr 2005] [aprox 5 telas]. Disponível em: http://www.rolim.com.br/2002/_pdfs/ poamericas.pdf.

7-Zavalloni M, Louis-Guérin C. L'égo-ecologie comme étude de l'interaction symbolique et imaginaire de soi et des autres. Sociologie et Sociétés 1987 oct; 19(2): 65-75.

8-Zavalloni M, Louis-Guérin C. Identité sociale et conscience. Introduction à l'égo ecologie. Quebec(CA): Les Presses de I'Université de Montreal; 1984.

9-Bar ton R. Psychosocial rehabilitation services in community support systems: a review of outcomes and policy recommendations. Psychiatric Services, [citado 30 mar 2007]. [aprox 9 telas] 1999. Disponível: http://ps.psychiatryonline.org/cgi/content/full/50/4/525

10-Pereira MAO. Representações da doença mental pela família do paciente. Interface: comunicação, saúde, educação. Botucatu (SP): 2003; 7(12):71-82
11-Peixoto G. Algumas considerações, com um pouco de história familiar, sobre a relação entre a loucura, a ética e a política no âmbito da saúde mental. In: Conselho Federal de Psicologia, organizador. Loucura, ética e política: escritos militantes. São Paulo (SP): Casa do Psicólogo 2003; p.66-71.

12-Koga M, Furegato ARF. Convivência com a pessoa portadora de esquizofrenia: sobrecarga familiar. Anais do V Encontro de Pesquisadores em Saúde Mental e IV Encontro de Especialistas em Enfermagem Psiquiátrica; 1997 abr. Ribeirão Preto (SP), Brasil: Scala; 1999. p.363-77.

13- Desviat M. A reforma psiquiátrica. Rio de Janeiro (RJ): FIOCRUZ; 1999.

14-Prefeitura do Rio de Janeiro (RI). Armazém de dados. [citado maio 2005] [aprox 2 telas] Disponível em: http:// www.armazemdedados.rio.rj.gov.br/index.htm.

15-0liveira MMB, Jorge MSB. Doente mental e sua relação com a família. Anais do V Encontro de Pesquisadores em Saúde Mental e IV Encontro de Especialistas em Enfermagem Psiquiátrica; 1997 abr. Ribeirão Preto (SP), Brasil: Scala; 1999. p.379-88.

16-Carvalho MC. Os desafios da desinstitucionalização. In: Figueiredo $A C$, Cavalcanti MT, organizadoras. A reforma psiquiátrica e os desafios da desinstitucionalização. Rio de Janeiro(R): IPUB/CUCA; 2001. p.0938.

17-Costa-Rosa A. 0 modo psicossocial: um paradigma das práticas sustitutivas ao modo asilar. In: Amarante PG, organizador. Ensaios: subjetividade, saúde mental e sociedade. Rio de Janeiro (RJ): FIOCRUZ; 2000. p.141-68.

18-Campos FCB. Desafios da gestão de rede atenção em saúde mental para 0 cuidar em liberdade. In: World Health Organization Mediterranean. International Debate. set 2003. [citado 04 maio 2005]. Disponível: http://wmc.who.int/images/uploaded/desafios.PDF 